AIP Applied Physics

\title{
Implication of oxygen vacancies on current conduction mechanisms in TiN/Zr1-xAlxO2/TiN metal-insulator-metal structures
}

\author{
A. Paskaleva, M. Lemberger, A. J. Bauer, and L. Frey
}

Citation: J. Appl. Phys. 109, 076101 (2011); doi: 10.1063/1.3565056

View online: http://dx.doi.org/10.1063/1.3565056

View Table of Contents: http://jap.aip.org/resource/1/JAPIAU/v109/i7

Published by the American Institute of Physics.

\section{Related Articles}

Non-planar substrate effect on the interface trap capacitance of metal-oxide-semiconductor structures with ultra thin oxides

J. Appl. Phys. 112, 094502 (2012)

Gate stack dielectric degradation of rare-earth oxides grown on high mobility Ge substrates

J. Appl. Phys. 112, 094501 (2012)

Leakage current asymmetry and resistive switching behavior of $\mathrm{SrTiO} 3$

Appl. Phys. Lett. 101, 173507 (2012)

An accurate characterization of interface-state by deep-level transient spectroscopy for Ge metal-insulatorsemiconductor capacitors with $\mathrm{SiO} 2 / \mathrm{GeO} 2$ bilayer passivation

J. Appl. Phys. 112, 083707 (2012)

Influence of the surface morphology on the channel mobility of lateral implanted $4 \mathrm{H}-\mathrm{SiC}(0001)$ metal-oxidesemiconductor field-effect transistors

J. Appl. Phys. 112, 084501 (2012)

\section{Additional information on J. Appl. Phys.}

Journal Homepage: http://jap.aip.org/

Journal Information: http://jap.aip.org/about/about_the_journal

Top downloads: http://jap.aip.org/features/most_downloaded

Information for Authors: http://jap.aip.org/authors

\section{ADVERTISEMENT}
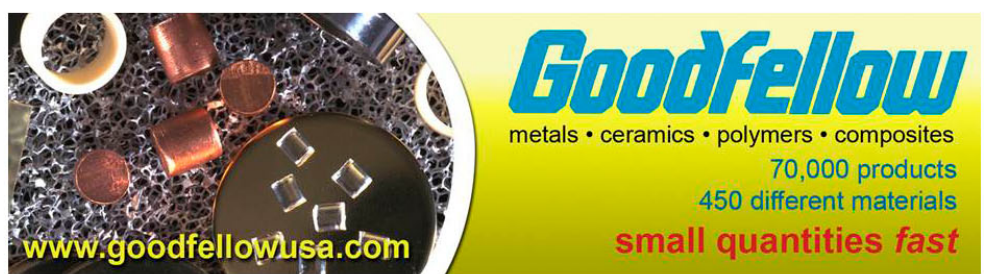


\title{
Implication of oxygen vacancies on current conduction mechanisms in $\mathrm{TiN} / \mathrm{Zr}_{1-\mathrm{x}} \mathrm{Al}_{\mathrm{x}} \mathrm{O}_{2} / \mathrm{TiN}$ metal-insulator-metal structures
}

\author{
A. Paskaleva, ${ }^{1, \text { a) }}$ M. Lemberger, ${ }^{2}$ A. J. Bauer, ${ }^{2}$ and L. Frey ${ }^{2,3}$ \\ ${ }^{1}$ Institute of Solid State Physics, Bulgarian Academy of Sciences, 72 Tzarigradsko Chaussee, 1784 Sofia, \\ Bulgaria \\ ${ }^{2}$ Fraunhofer Institute for Integrated Systems and Device Technology, Schottkystrasse 10, 91058 Erlangen, \\ Germany \\ ${ }^{3}$ Chair of Electron Devices, University Erlangen-Nuremberg, Cauerstrasse 6, 91058, Erlangen, Germany
}

(Received 14 January 2011; accepted 17 February 2011; published online 6 April 2011)

\begin{abstract}
The dominating conduction mechanisms through $\mathrm{TiN} / \mathrm{Zr}_{1-\mathrm{x}} \mathrm{Al}_{\mathrm{x}} \mathrm{O}_{2} / \mathrm{TiN}$ capacitors have been investigated over a wide temperature range $(25 \mathrm{~K}$ to $430 \mathrm{~K})$ in order to obtain information about the traps which cause the current transport. Single positive charged oxygen vacancies are the principal transport sites which participate in all mechanisms observed. However, the conduction mostly defined by intrinsic traps could also be strongly influenced by defects originating from undesirable high-k/metal gate interface reactions which could act as real traps or as transport sites. (C) 2011 American Institute of Physics. [doi:10.1063/1.3565056]
\end{abstract}

The large amount of traps in high-k materials defines the substantial difference to $\mathrm{SiO}_{2}$ with regard to the dominating current conduction mechanism(s). In high-k materials, the conduction mechanisms are usually trap-related and the domination of a certain mechanism depends on many parameters: trap parameters; stack parameters; measurement conditions. Such a variety of parameters influencing the conduction process results in a wide diversity of mechanisms observed. The thorough investigation of conduction mechanisms could give valuable information on the trap parameters as well as on structural alterations in the layers. A better understanding of the trap participation in the conduction could be obtained by measurements at very low temperatures, as in this case, temperature activated conduction processes are suppressed. Hence, only temperature independent processes may operate. As trapping is slightly temperature dependent while detrapping is a strongly temperature stimulated process, ${ }^{1-3}$ it is expected that at very low temperatures detrapping does not occur, hence the influence on the leakage current of trapping with respect to detrapping will be maximized.

In this work, implications of traps on conduction mechanisms in $\mathrm{TiN} / \mathrm{Zr}_{1-\mathrm{x}} \mathrm{Al}_{\mathrm{x}} \mathrm{O}_{2} / \mathrm{TiN}$ metal-insulator-metal (MIM) capacitors are investigated by performing I-V measurements in a wide temperature range of $25 \mathrm{~K}$ to $430 \mathrm{~K}$. Al-doped $\mathrm{ZrO}_{2}$ $\left(\mathrm{Zr}_{1-\mathrm{x}} \mathrm{Al}_{\mathrm{x}} \mathrm{O}_{2}\right)$ layers were grown on a bottom electrode of 10 $\mathrm{nm}$ thick TiN by atomic layer deposition (ALD) at a temperature of $275{ }^{\circ} \mathrm{C}$ by using TEMAZ $\left(\mathrm{Zr}\left[\mathrm{N}\left(\mathrm{CH}_{3}\right) \mathrm{C}_{2} \mathrm{H}_{5}\right]_{4}\right)$ and TMA $\left(\mathrm{Al}\left[\mathrm{CH}_{3}\right]_{3}\right)$ as metal precursors, and ozone as oxidant. The Al content was about 10 at. $\%$ and the thickness $t_{\mathrm{ox}}$ was $10 \mathrm{~nm} .10 \mathrm{~nm}$ TiN as top electrode was chemically vapor deposited at about $450{ }^{\circ} \mathrm{C}$ followed by a tungsten contact.

The $\mathrm{J}-\mathrm{V}$ curves are almost temperature independent in the range 25-175 K [Fig. 1(a)]. To minimize the displacement current, the voltage was changed stepwise with long enough delay time. The measurements at two polarities were performed on different capacitors to eliminate any instability

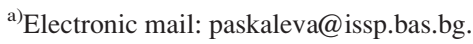

and polarization effects which may arise from the alternate change of polarity. Despite the structural symmetry of the MIM capacitors, there is a polarity asymmetry at $25 \mathrm{~K}$ while at $300 \mathrm{~K}$ symmetrical curves have been obtained [inset Fig. 1(a)]. As discussed previously, ${ }^{4,5} \mathrm{a} \mathrm{TiO}_{\mathrm{x}}$-like interfacial layer is formed at the high-k/bottom electrode interface due to an interaction between $\mathrm{TiN}$ and $\mathrm{O}_{3}$. The asymmetry is assigned to electron trapping at this interface which modifies the electric field and shifts the curves to higher voltages for positive polarity. With increasing temperature above $175 \mathrm{~K}$, part of the trapped electrons are released which results in an increase of the current. At $300 \mathrm{~K}$ and positive gate bias, the two mechanisms - the current decrease due to trapping and the increase due to detrapping - are almost in equilibrium, hence do not affect the J-V curve, which coincides with the curve measured at negative bias. With a further increase of temperature, detrapping should be stimulated and the current for positive polarity should become larger, which is indeed observed [inset Fig. 1(b)]. A possible difference in barrier heights at the two interfaces due to existence of a thin $\mathrm{TiO}_{\mathrm{x}}$ layer at the high-k/bottom electrode interface could also be a reason for the asymmetry. ${ }^{6}$ However, this is more unlikely as a difference in barrier heights should not depend on temperature, hence similar asymmetry should be obtained at all temperatures. Therefore, the polarity asymmetry of the curves resulted from the trapping/detrapping at the high-k/bottom electrode interface and the shift $\Delta \mathrm{V}_{\mathrm{G}}$ of about $0.4-0.5 \mathrm{~V}$ between the two $\mathrm{J}-\mathrm{V}$ curves at $25 \mathrm{~K}$ corresponds to a trapped charge density $\mathrm{N}_{\mathrm{ot}}$ of about $8 \times 10^{12} \mathrm{~cm}^{-2}\left(\mathrm{~N}_{\mathrm{ot}}=\mathrm{C} \Delta \mathrm{V}_{\mathrm{G}}\right)$. As the curves are temperature independent up to $175 \mathrm{~K}$, Fowler-Nordheim (FN) tunneling $\left(J=A E^{2} \exp \left(-\mathrm{B} / \mathrm{E} \phi_{b}{ }^{3 / 2}\right)\right.$ is suggested to govern the conduction in this temperature range and a barrier height of $1.3 \mathrm{eV}$ for negative polarity is obtained (assuming an effective electron mass $m^{*}$ in $\mathrm{ZrO}_{2}$ of $0.25 \mathrm{~m}_{0}{ }^{7}$ $\mathrm{m}_{0}$ is the free electron mass). For positive polarity, a similar value $(1.4 \mathrm{eV})$ is calculated (in this case, the electric field is corrected with the field created by the trapped charge, i.e., the field at the bottom electrode is $\left.\mathrm{E}=\left(\mathrm{V}_{\mathrm{G}}-\Delta \mathrm{V}_{\mathrm{G}}\right) / \mathrm{t}_{\mathrm{ox}}\right)$. But, 


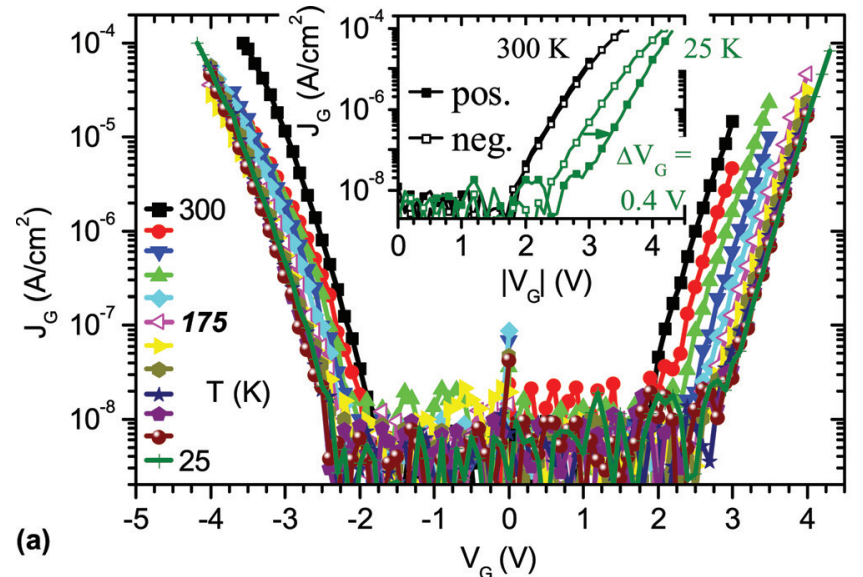

(a)

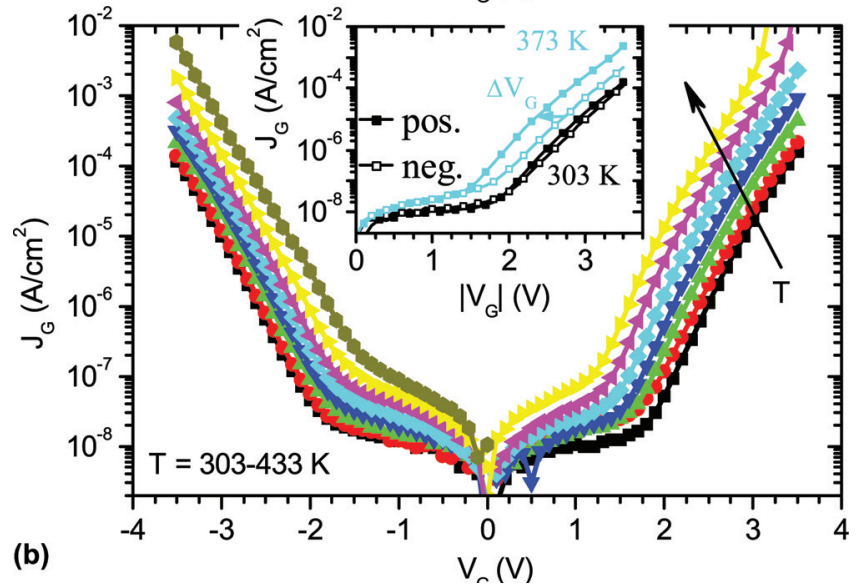

FIG. 1. (Color online) J-V curves of $\mathrm{TiN} / \mathrm{Zr}_{1-\mathrm{x}} \mathrm{Al}_{\mathrm{x}} \mathrm{O}_{2} / \mathrm{TiN}$ capacitors measured (a) from 25 to $300 \mathrm{~K}$, and (b) from 300 to $430 \mathrm{~K}$. The insets compare the $\mathrm{J}-\mathrm{V}$ curves at both top electrode polarities and different temperatures.

estimation of the barrier height from structural point of view gives significantly larger values. This estimation is performed by taking an electron affinity of $\mathrm{ZrO}_{2}$ of $2.5 \mathrm{eV}$ (Ref. 8) and TiN work function of $4.7 \mathrm{eV}$ into account, which ideally gives a value of $2.2 \mathrm{eV}$ for the barrier height. However, charge transfer across interfaces is a well-recognized phenomenon, which results in a formation of dipoles modifying this barrier. Hence, it is assumed that the barrier height is slightly lower (e.g., 1.7 to $2.0 \mathrm{eV}$ ). The difference to the value obtained from $\mathrm{J}-\mathrm{V}$ measurements make us conclude that the conduction is governed rather by a field-assisted tunneling $(\mathrm{FAT})^{9}$ than FN tunneling. In the FAT process, the electrons tunnel from the electrode to the traps, and then from traps to the conduction band (CB) of the dielectric. The second stage of this process is similar to FN tunneling, hence it is represented by the same equation as $\mathrm{FN}$, where the barrier height $\phi_{\mathrm{b}}$ is replaced by the energy location $\phi_{\mathrm{t}}$ of traps. ${ }^{9,10}$ Therefore, at very low temperatures, the conduction process is symmetric (i.e., FAT through $1.3 \mathrm{eV}$ bulk traps) for both polarities and the asymmetry of $\mathrm{J}-\mathrm{V}$ curves is due to trapped electrons at the high-k/bottom TiN interface. The $1.3 \mathrm{eV}$ trap level is consistent with the first ionization level $\mathrm{V}_{\mathrm{O}}{ }^{+}$of oxygen vacancies in $\mathrm{ZrO}_{2}$, whose energy position has been theoretically calculated at $1.2-1.4 \mathrm{eV}$ (Ref. 11).

Next, the J-V curves measured at higher temperatures [Fig. 1(b)] will be considered. At low fields and for both
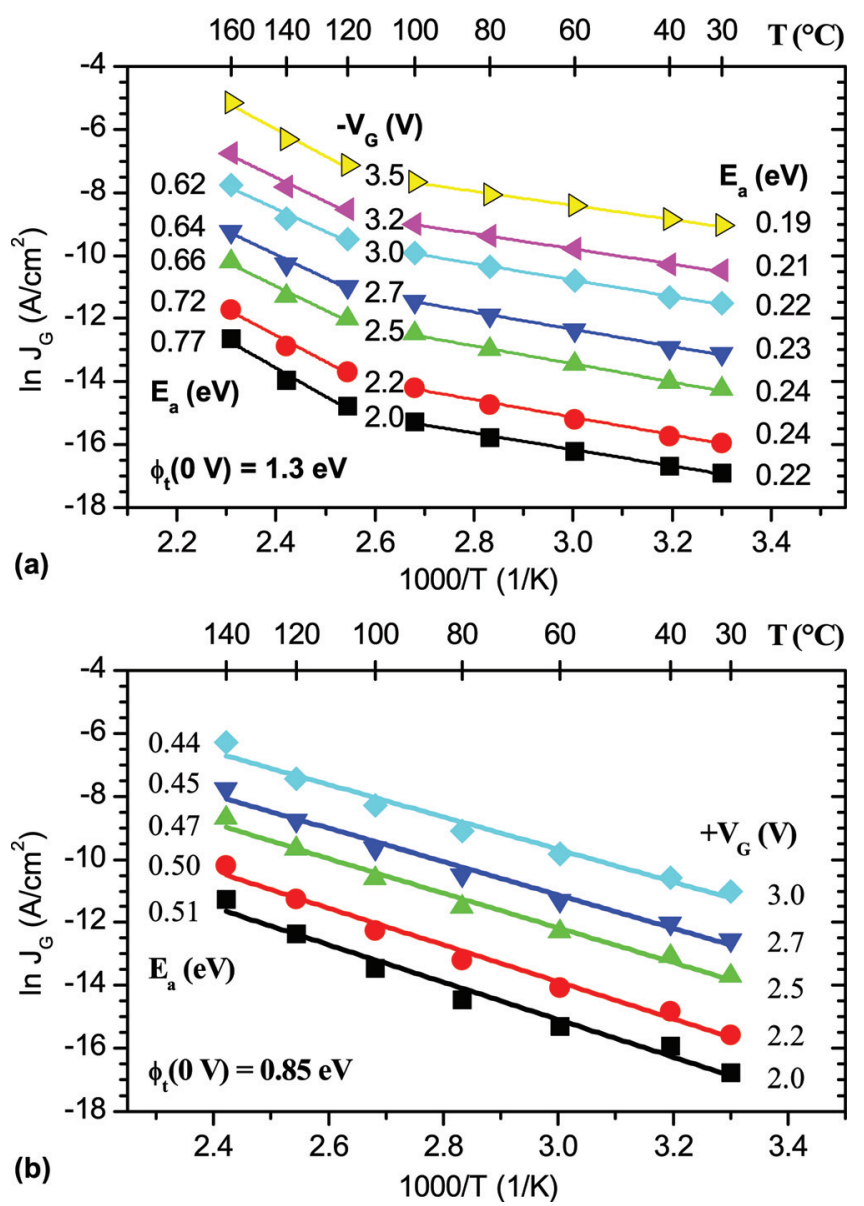

FIG. 2. (Color online) Arrhenius plot of current density at (a) negative, and (b) positive top electrode polarity.

polarities $\left(\mathrm{V}_{\mathrm{G}}<\mathrm{I} \pm 1.5 \mathrm{I} \mathrm{V}\right)$, the current density increases only slightly with applied voltage and temperature. The activation energy $E_{a}$ of the conduction process, is about $0.25-0.3 \mathrm{eV}$ for both polarities without any clear dependence on the applied voltage. There is an apparent polarity asymmetry at higher voltages which is better revealed in an Arrhenius plot of the current (Fig. 2). At negative polarity [Fig. 2(a)], two different processes govern the current. The first one dominates in the range 300-373 K and shows relatively weak temperature dependence. The activation energy $E_{a}$ for this process is found to be about $0.2-0.25 \mathrm{eV}$. Note that these values are very similar to the activation energy found at low fields i.e., the two processes have the same activation energy, but substantially different field dependence. With increasing the temperature above $373 \mathrm{~K}$, significantly larger values of the activation energy have been obtained and a systematic decrease of $E_{a}$ from $0.77 \mathrm{eV}$ to $0.62 \mathrm{eV}$ is observed [Fig. 2(a)]. This fact strongly suggests the domination of Poole-Frenkel conduction at these measurement conditions. From an $\mathrm{E}_{\mathrm{a}}$ versus $\mathrm{V}^{1 / 2}$ plot, the energy location of the traps $\phi_{\mathrm{t}}(0 \mathrm{~V})$ is found to be $1.3 \mathrm{eV}$ (i.e., the same traps which mediate the FAT).

The following mechanisms for the current conduction for negative polarity (Fig. 3) are suggested. The dominating mechanism at very low temperatures is FAT through $1.3 \mathrm{eV}$ bulk traps [Fig. 3(a)], which can be assigned to $\mathrm{V}_{\mathrm{O}}{ }^{+}$in (Aldoped) $\mathrm{ZrO}_{2}$. At low fields and $\mathrm{T}>300 \mathrm{~K}$ the current density increases only slightly and is due to trap assisted tunneling 
(a)

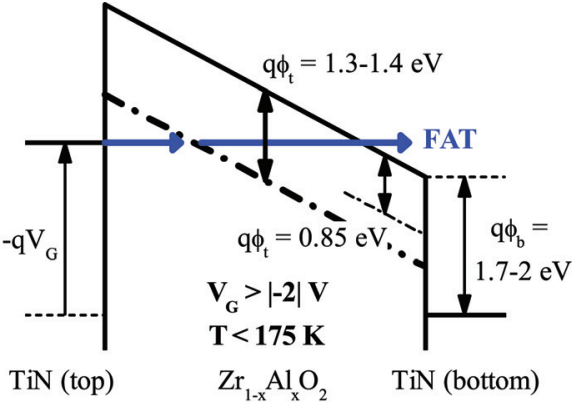

(c)

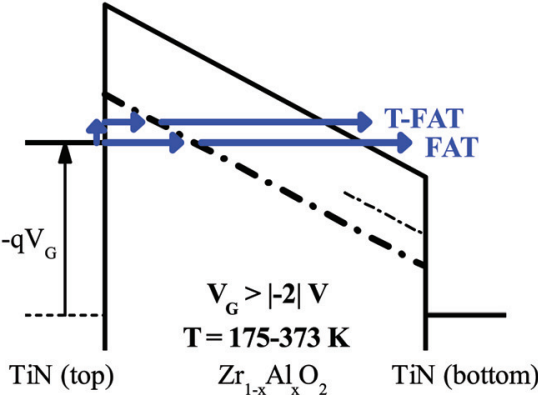

(b)

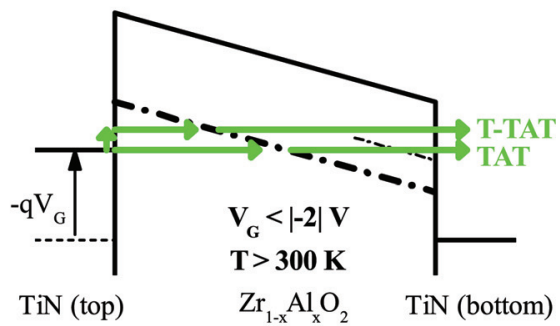

(d)

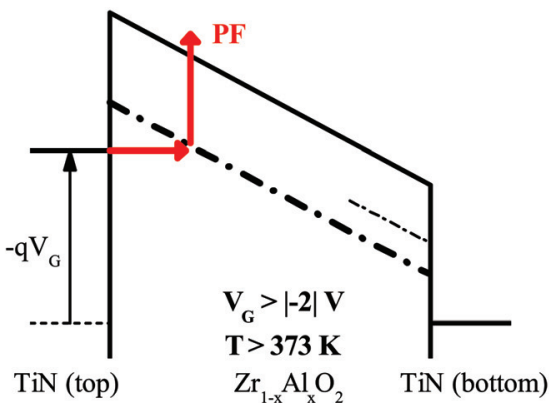

FIG. 3. (Color online) Schematic representation of the dominating conduction mechanisms at different measurements conditions: (a) $\mathrm{V}_{\mathrm{G}}>|-2| \mathrm{V}, \mathrm{T}=25-$ $175 \mathrm{~K}$; (b) $\mathrm{V}_{\mathrm{G}}<\mathrm{I}-2 \mathrm{I} \mathrm{V}, \mathrm{T}=300-433 \mathrm{~K}$; (c) $\mathrm{V}_{\mathrm{G}}>|-2| \mathrm{V}, \mathrm{T}=175-373 \mathrm{~K}$; (d) $\mathrm{V}_{\mathrm{G}}>|-2| \mathrm{V}, \mathrm{T}>373 \mathrm{~K}$
(TAT) [Fig. 3(b)]. In the TAT process, the electrons tunnel from the electrode to the trap and then to the other electrode, without entering the conduction band of the dielectric. As the layer is relatively thick, the probability for this process is not very high, which explains the low leakage current. We suggest that the traps participating in TAT are the same ones which participate in FAT and PF mechanisms. With increasing temperature, the first stage of the process is stimulated due to thermal excitation of the tunneling electrons (T-TAT) and the activation energy of this process is about $0.25 \mathrm{eV}$. The increase of voltage above $2 \mathrm{~V}$ changes the barrier for the tunneling electrons from being trapezoidal to triangular shaped (i.e., this is in a good agreement with the suggested (Al-doped) $\mathrm{ZrO}_{2} / \mathrm{TiN}$ barrier height of $2 \mathrm{eV}$, Fig. 3(c)) which results in a change of the field dependence of the current. In other words, at about $-2 \mathrm{~V}$, a change from TAT to FAT occurs. The weak temperature dependence in the range $175-373 \mathrm{~K}$ is again related to the thermal excitation of electrons at the first stage of the tunneling process (T-FAT) [Fig. 3(c)], hence the same activation energy is obtained. With the increase of temperature above $373 \mathrm{~K}$, the probability for the thermal excitation from the traps to the $\mathrm{CB}$ of dielectric increases and the PF process becomes the dominant mechanism [Fig. 3(d)] which explains the stronger temperature dependence.

The conduction for positive polarity is substantially different and at $\mathrm{V}_{\mathrm{G}}>2 \mathrm{~V}$ and $\mathrm{T} \geq 300 \mathrm{~K}$ only one temperature activated process operates [Fig. 2(b)]. The activation energy is also field dependent implying the domination of PF conduction and the energy location of traps $\phi_{\mathrm{t}}(0 \mathrm{~V})$ is found to be about $0.85 \mathrm{eV}$ below the $\mathrm{CB}$ of the dielectric. Therefore, the transport at very low temperatures is dominated by traps at $1.3 \mathrm{eV}$, whereas at higher temperatures different traps govern the current for the two polarities. A feasible explanation is that the $0.85 \mathrm{eV}$ level is related to defects resulting from the reactions at the high-k/bottom TiN. At very low temperatures, these defects act as traps, while at high fields and high temperatures they serve as transport sites due to temperature stimulated detrapping.

In summary, the results reveal the existence of a trap level at about $1.3 \mathrm{eV}$ below the $\mathrm{CB}$ of $\mathrm{Zr}_{1-\mathrm{x}} \mathrm{Al}_{\mathrm{x}} \mathrm{O}_{2}$ which fully controls the transport of electrons at negative polarity and gives rise to several conduction mechanisms that dominate at different conditions. According to theoretical calculations, this trap level is due to single positively charged oxygen vacancies in $\mathrm{ZrO}_{2}$. The interfacial layer formed by undesirable high-k/ metal gate reactions is a location of increased trapping which leads to asymmetrical electrical behavior and impacts substantially the conduction process defined by the intrinsic traps.

The work was partly financially supported by the Bulgarian National Science Fund (Grant No. DTK02/50) and by the German Federal Ministry of Education and Research (Grant No. 01M3171A). A. Paskaleva is thankful to Alexander von Humboldt Foundation for financial support.

${ }^{1}$ S. Kalpat, H.-H. Tseng, M. Ramon, M. Moosa, D. Tekleab, P. J. Tobin, D. C. Gilmer, R. I. Hedge, C. Capasso, C. Tracy, and B. E. White Jr., IEEE Trans. Dev. Mater. Reliab. 5, 26 (2005).

${ }^{2}$ D. Misra, and N. A. Chowdhury, ECS Trans. 2, 311 (2006).

${ }^{3}$ M. Aoulaiche, M. Houssa, R. Degraeve, G. Groeseneken, S. DeGendt, and M. M. Heyns, Proc. of 35th European Solid State Device Research Conference (Grenoble, France, 12-16 September, 2005), p. 197.

${ }^{4}$ W. Weinreich, R. Reiche, M. Lemberger, G. Jegert, J. Müller, L. Wilde, T. Teichert, J. Heitmann, E. Erben, L. Oberbeck, U. Schroeder, A. J. Bauer and H. Ryssel, Microelectron. Eng. 86, 1826 (2009).

${ }^{5}$ Paskaleva, M. Lemberger, A. J. Bauer, W. Weinreich, J. Heitmann, E. Erben, U. Schroeder, and L. Oberbeck, J. Appl. Phys. 106, 054107 (2009).

${ }^{6}$ U. Schroeder, W. Weinreich, E. Erben, J. Mueller, L. Wilde, J. Heitmann, R. Agaiby, D. Zhou, G. Jegert, and A. Kersch, ECS Trans. 25, 357 (2009). ${ }^{7}$ C. L. Hinkle, C. Fulton, R. J. Nemanich, and G. Lucovsky, Microelectron. Eng. 72, 257 (2004).

${ }^{8}$ J. Robertson, J. Vac. Sci. Technol. B 18, 1785 (2000).

${ }^{9}$ K. Y. Lim, D. G. Park, H. J. Cho, J. J. Kim, J. M. Yang, I. S. Choi, I. S. Yeo, and J. W. Park, J. Appl. Phys. 91, 414 (2002).

${ }^{10}$ B. L. Yang, P. T. Lai, and H. Wong, Microelectron. Reliab. 44, 709 (2004).

${ }^{11}$ J. Robertson, K. Xiong, and B. Falabretti, IEEE Trans. Dev. Mater. Reliab. 5, 84 (2005). 